\title{
Papers
}

\section{Trends in rates of different forms of diagnosed coronary heart disease, 1978 to 2000: prospective, population based study of British men}

\author{
Fiona C Lampe, Richard W Morris, Mary Walker, A Gerald Shaper, Peter H Whincup
}

\begin{abstract}
Objective To examine trends over time in rates of different forms of diagnosed coronary heart disease among British men, during a period in which mortality due to coronary heart disease has been declining.

Design Prospective cohort study covering the period 1978-80 to $1998-2000$.

Participants 7735 men, aged 40-59 at entry, randomly selected from one general practice in each of 24 British towns.

Main outcome measures Trends in the rates of major coronary events, first diagnosed angina and first diagnosed coronary heart disease (any fatal or non-fatal documented event or diagnosis). Events were ascertained from NHS central registers and reviews of medical records from general practices. Results Over the 20 year period, 1561 major coronary events occurred; 1087 and 1816 men had new diagnoses of angina and coronary heart disease, respectively. The age adjusted annual relative changes were $-3.6 \%$ (95\% confidence interval $-4.8 \%$ to $-2.4 \%, \mathrm{P}<0.001)$ for all major coronary events, $2.6 \%$ $(1.1 \%$ to $4.0 \%, \mathrm{P}<0.001)$ for first diagnosed angina and $-0.8 \%$ $(-1.8 \%$ to $0.3 \%, \mathrm{P}=0.18)$ for first diagnosed coronary heart disease. The fall in major coronary events occurred across all categories of event (fatal and non-fatal, first and recurrent). Similarly, first diagnosed angina increased for both uncomplicated angina and angina after myocardial infarction. The age adjusted annual relative change in case fatality at 28 days of first major coronary events was $-1.4 \%$ ( $-3.1 \%$ to $0.4 \%$, $\mathrm{P}=0.12$ ).

Conclusions Among British middle aged men, a substantial decline in the rate of major coronary events over the past two decades seems to have been largely offset by an increase in the incidence of diagnosed angina. Overall there was little change in the incidence of first diagnosed coronary heart disease. A continuing need exists for resources and services for coronary heart disease in general, and for new angina in particular.
\end{abstract}

\section{Introduction}

Since the late 1970s, rates of coronary heart disease death in the United Kingdom have fallen by more than $50 \%{ }^{1}$ Data from the monitoring trends and determinants in cardiovascular disease (MONICA) studies ${ }^{2}$ and a previous report from the British Regional Heart Study ${ }^{3}$ showed that this trend has been due in part to a fall in the rate of occurrence of new major coronary events. However, despite increasing evidence of falling incidences of myocardial infarction in Britain and other countries, little is known about trends in rates of "lesser" diagnoses, particularly angina, a condition that makes a large contribution to the total incidence of diagnosed coronary heart disease. ${ }^{4}$ In Britain, angina is commonly diagnosed and managed in primary care, ${ }^{56}$ and studies based on cases in patients admitted to hospital may not present a complete picture of medically recognised disease in the population. Using information from general practice medical record reviews we examined trends in rates of different forms of diagnosed coronary heart disease in the British Regional Heart Study during 20 years of follow-up, from 1978-80 to 1998-2000. In particular we assessed whether trends in the incidence of diagnosed angina and diagnosed coronary heart disease overall have followed a similar pattern to trends observed for rates of major coronary events. Changes in rates of different forms of diagnosed coronary heart disease have implications for prevention policy and health provision.

\section{Methods}

The British Regional Heart Study is a prospective study of 7735 men aged 40-59 years at baseline (1978-80), who were randomly selected from one general practice in each of 24 British towns. ${ }^{7}$ The sample includes all major geographical regions in Britain and is representative of the male population in terms of social class distribution. Information from participants' questionnaires at study entry was used to ascertain diagnoses of pre-existing coronary heart disease. ${ }^{8}$ Participants were followed over 20 years through NHS central registers and regular reviews of medical records in general practices (including hospital and clinic correspondence) for death due to coronary heart disease, first and recurrent definite myocardial infarctions, first and recurrent possible myocardial infarctions, and first diagnosis of angina. ${ }^{9}$ About $1 \%$ of men have been lost to follow-up.

\section{End points}

We examined trends in rates of diagnosed (medically recorded) coronary heart disease only. End points are defined in table 1 . We considered three main categories: all major coronary events (subdivided into death due to coronary heart disease and non-fatal definite myocardial infarction, and also into first major coronary event and recurrent major coronary events); first diagnosed angina (subdivided into uncomplicated angina, and angina post myocardial infarction); and first diagnosed coronary heart disease (any fatal or non-fatal documented coronary event or diagnosis). Three end points-all major coronary events, nonfatal definite myocardial infarction, and recurrent major coronary events-include multiple recurrent events from 


\begin{tabular}{|c|c|c|}
\hline End point & No of events & Definition \\
\hline All major coronary events: & 1561 & $\begin{array}{l}\text { Death due to coronary heart disease or non-fatal definite myocardial infarction. Recurrent events } \\
\text { for individual subjects included }\end{array}$ \\
\hline Death due to coronary heart disease & 751 & Death with ICD-9 codes $410-414$, according to underlying cause on death certificate \\
\hline Non-fatal definite myocardial infarction & 810 & $\begin{array}{l}\text { Medical record of acute coronary heart disease event with at least two of: history of severe } \\
\text { prolonged chest pain, evidence of myocardial infarction on electrocardiography, cardiac enzymes } \\
\text { abnormalities, with survival for } \geq 28 \text { days after onset of symptoms. Recurrent events included }\end{array}$ \\
\hline First major coronary events & 1141 & $\begin{array}{l}\text { First occurrence of major coronary heart disease event. Subjects with pre-existing myocardial } \\
\text { infarction diagnosis at study entry excluded }\end{array}$ \\
\hline Recurrent major coronary events & 420 & Repeat occurrence of major coronary heart disease event. Recurrent events included \\
\hline First diagnosed angina: & 1087 & $\begin{array}{l}\text { First medical record of possible or definite angina according to clinical diagnosis (history of typical } \\
\text { effort or stress related chest pain). Confirmation from investigative tests not required. Subjects } \\
\text { with pre-existing angina diagnosis at study entry excluded }\end{array}$ \\
\hline Uncomplicated angina & 840 & First diagnosed angina if it occurred without pre-existing definite myocardial infarction \\
\hline Angina after myocardial infarction & 247 & First diagnosed angina if it occurred after a definite myocardial infarction \\
\hline First diagnosed coronary heart disease & 1816 & $\begin{array}{l}\text { First occurrence of any of: coronary heart disease death, non-fatal definite myocardial infarction, } \\
\text { non-fatal possible myocardial infarction }{ }^{*} \text {, diagnosed angina. Subjects with pre-existing myocardial } \\
\text { infarction or angina diagnosis at study entry excluded }\end{array}$ \\
\hline
\end{tabular}

*Possible myocardial infarction was defined as a medical record of an acute coronary heart disease event not fulfilling the criteria for definite myocardial infarction.

individual subjects, whereas the remainder are restricted to the first ever events only.

\section{Statistical analysis}

We ascertained numbers of events and person years at risk during four exact five year follow-up periods from each subject's baseline assessment date: $1978-80$ to $1983-5,1983-5$ to $1988-90$, 1988-90 to $1993-5$, and $1993-5$ to $1998-2000$. We used Poisson regression to estimate trends in event rates, with date of follow-up period as a continuous covariate and person time of follow-up as an offset. We used quadratic or cubic polynomials as necessary to adjust for age, in order to account for the non-linear association over the age range included in analyses. We used generalised estimating equations with an autoregressive correlation structure to account for recurrent events from individual subjects (using SAS, release 8.02, SAS Institute, Cary, NC, USA). Accounting for clustering owing to initial town of selection had

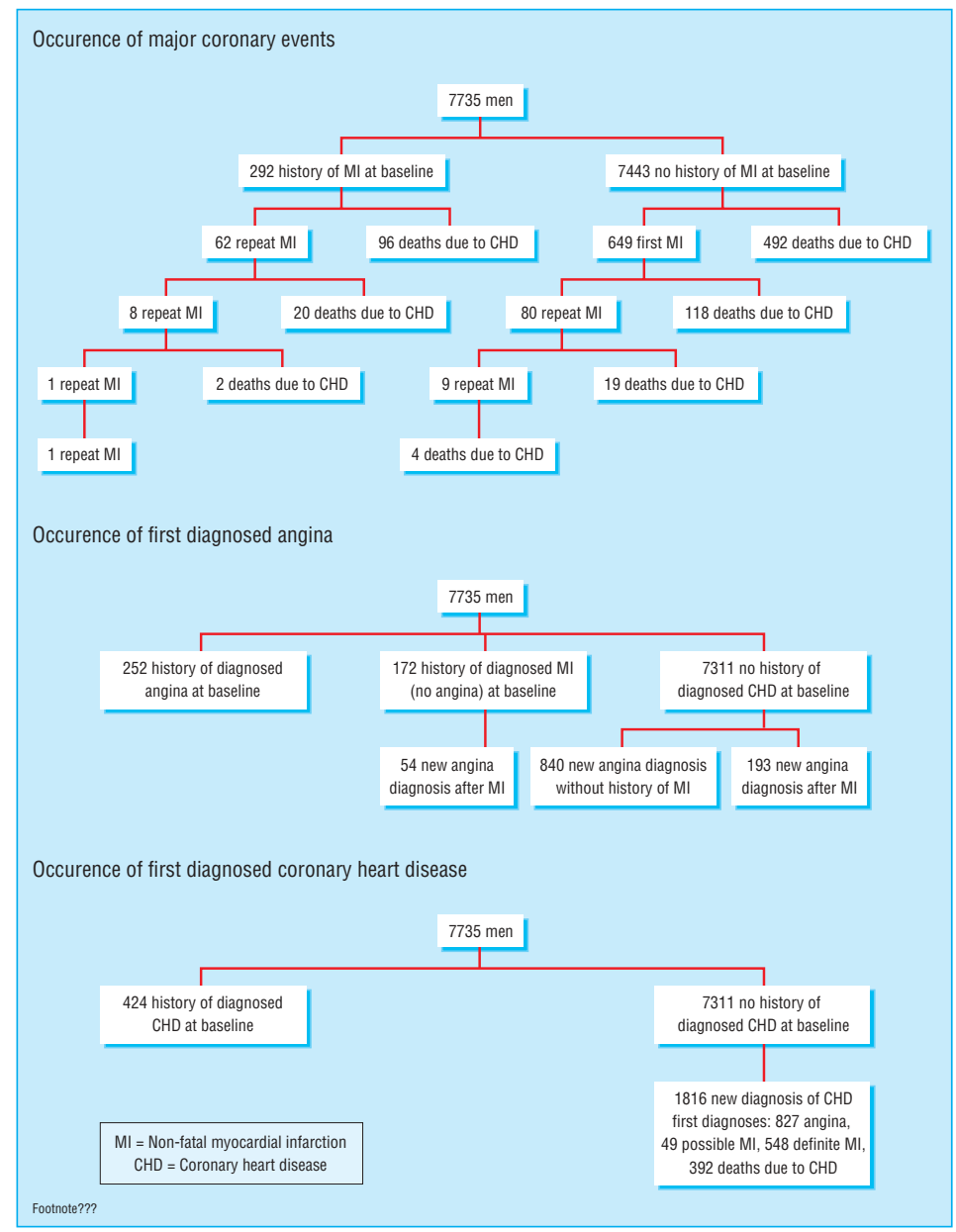

Fig 1 Occurrence of coronary events among 7735 men during 20 years of follow-up 
Table 2 Age adjusted estimates of annual relative percentage changes in rates of coronary events

\begin{tabular}{|c|c|c|c|c|}
\hline \multirow[b]{2}{*}{ Event rate } & \multirow{2}{*}{$\begin{array}{c}\text { Total person years } \\
\text { at risk }\end{array}$} & \multirow[b]{2}{*}{ No of events } & \multicolumn{2}{|c|}{ Age adjusted annual relative percentage change $(95 \% \mathrm{Cl})^{*}$} \\
\hline & & & Entire 20 year period (1978-80 to $1998-2000)$ & Final 10 year period (1988-90 to $1998-2000)$ \\
\hline All major coronary events: & 138111 & 1561 & $-3.6(-4.8$ to $-2.4, P<0.001)$ & $-3.6(-6.3$ to -0.9$)$ \\
\hline Coronary heart disease death & 138111 & 751 & $-4.8(-6.5$ to $-3.1, P<0.001)$ & \\
\hline Non-fatal definite myocardial infarction & 138111 & 810 & $-3.0(-4.6$ to $-1.4, P<0.001)$ & \\
\hline First major coronary event & 128916 & 1141 & $-3.5(-4.8$ to $-2.1, P<0.001)$ & \\
\hline Recurrent major coronary events & 9195 & 420 & $-3.9(-6.1$ to $-1.7, P<0.001)$ & \\
\hline First diagnosed angina: & 126228 & 1087 & 2.6 (1.1 to $4.0, P<0.001$ ) & $2.9(-0.3$ to 6.2$)$ \\
\hline Uncomplicated angina & 121332 & 840 & 2.4 (0.8 to $4.1, P=0.003)$ & \\
\hline Angina after myocardial infarction & 4896 & 247 & $5.1(2.1$ to $8.2, P<0.001)$ & \\
\hline First diagnosed coronary heart disease & 121024 & 1816 & $-0.8 \quad(-1.8$ to $0.3, P=0.18)$ & $-0.4(-2.9$ to 2.2$)$ \\
\hline
\end{tabular}

*Estimates obtained using Poisson regression, with generalised estimating equation estimates for the following end points: all major coronary heart disease events, non-fatal myocardial infarction, recurrent major coronary events. Adjusted for age and age squared (all end points) and age cubed (all major coronary events, first major coronary event, and first diagnosed coronary heart disease for 20 year follow-up).

little effect on standard errors of trend estimates; we present unadjusted results. Trends are expressed as the average annual relative change in event rate with $95 \%$ confidence interval. For example, a rate ratio of 0.970 is presented as a relative rate change of $-3.0 \%$. We also examined trends in the case fatality of first major coronary events (percentage fatal within 28 days), using Poisson regression (as this provides the risk ratio rather than the odds ratio ${ }^{10}$ ), with date of event and age at event as covariates. We used tests of interaction to assess social class differences in trends, with each subject's social class classified as "non-manual" or "manual," according to occupation at entry into the study.

\section{Results}

Figure 1 shows the occurrence of coronary events and diagnoses among the 7735 men during 20 years of follow-up; total numbers of events in each category are given in table 1 . Overall there were 1561 major coronary events; 1087 and 1816 men had new diagnoses of angina and coronary heart disease respectively. Figure 2 shows age specific trends for the three main end points. Table 2 gives age adjusted estimates of annual trends over the 20 year period, for all event rates, presented as relative percentage changes. The rate of major coronary events fell substantially over the period by an average of $3.6 \%$ per year. The decline occurred for both fatal and non-fatal major coronary events (although it was greater for fatal events), and for both first and recurrent major coronary events (being of similar magnitude in each case). In contrast to rates of major coronary events, the rate of first diagnosed angina increased during the 20 year period, by an average of 2.6\% per year. This increase was apparent for uncomplicated angina and angina diagnosed after myocardial infarction, but it was larger for angina diagnosed after myocardial infarction. Because of the opposing trends in major coronary events and angina, the rate of first diagnosed coronary heart disease changed little over the 20 year period. Trend estimates for the last 10 year period of follow-up (1988-90 to 1998-2000) are also given in table 2 for the three main end points. These indicate the same pattern of opposing trends for major coronary events and angina, and no clear change in the rate of first diagnosed coronary heart disease. Of all 1141 first major coronary events, 492 were fatal within 28 days. The average annual decline in case fatality at 28 days of first major coronary events was moderate and non-significant (relative change in risk $-1.4,95 \%$ confidence interval -3.1 to 0.4 , $\mathrm{P}=0.12$ over the 20 year period).

The rate of major coronary events fell among men from both manual and non-manual social class groups (annual changes
$-3.3 \%$ for manual and $-4.6 \%$ for non-manual), and the rate of diagnosed angina increased (annual changes 2.6\% and 2.7\%, respectively) over the 20 year period. We found no evidence that the magnitude of these trends differed according to social class group (interaction tests: $\mathrm{P}=0.31$ for major coronary events and $\mathrm{P}=0.99$ for diagnosed angina).

\section{Discussion}

From 1978 to 2000, while rates of all categories of major coronary events declined among British men, the incidence of diagnosed angina increased, resulting in no apparent change in the overall incidence of diagnosed coronary heart disease.

\section{Strengths and limitations of the study}

The strengths of this population based study include the geographically and socially representative nature of the study sample, the comprehensive ascertainment of coronary heart disease diagnoses from general practice, and the very high rate of follow-up. The limitations include the fact that trends are based on single measures of angina and other coronary heart disease from the medical record reviews. These measures may be subject to inaccuracies because of the original records and the review process. In this study, comparisons between medical record review and participants' self report for coronary heart disease diagnoses show good agreement, ${ }^{11} 12$ giving support to the validity of these measures. Diagnoses of angina did not require fulfilment of specific objective criteria and therefore reflect diagnosis as it occurred in clinical practice, not necessarily certain confirmed coronary disease. We included "possible" documented cases of angina as the use of investigative tests has probably varied between practices and over time. ${ }^{13}$ The trend in angina was at least as strong when "possible" cases (which comprised about $12 \%$ of the total cases) were removed (average annual change $3.7 \%, 95 \%$ confidence interval $2.1 \%$ to $5.3 \%$ ). The trend estimates presented in this report are driven by data from the middle age groups, and are not necessarily generalisable to other age groups, or to women. The cohort design of the study prohibited investigation of age related heterogeneity in trends.

\section{Trends in major coronary heart disease}

We previously reported that among middle aged British men the rate of major coronary events fell from 1978-1995 by an average of $2.5 \%$ per year. ${ }^{3}$ These results indicate that the decline in major coronary events has continued just as strongly from the mid 1990s onward. Substantial declines in rates of both first and recurrent myocardial infarction have contributed, indicating both a fall in incidence and an improvement in prognosis of myocardial infarction. These trends in acute event rates are likely 
to be due both to changes in coronary risk factors in Britain and, perhaps to a lesser extent, improvements in treatment. ${ }^{14-18}$ In this study, the fall in 28 day case fatality of first major coronary events was modest. A similar pattern of marked declines in both incidence and recurrence of myocardial infarction but a smaller decline in case fatality has been reported for the Finnish MONICA population during the period $1983-97 .^{19}$ This may indicate that, in these populations, changes in primary and secondary preventive treatments have had a greater role than changes in acute coronary care. However, unless case fatality is

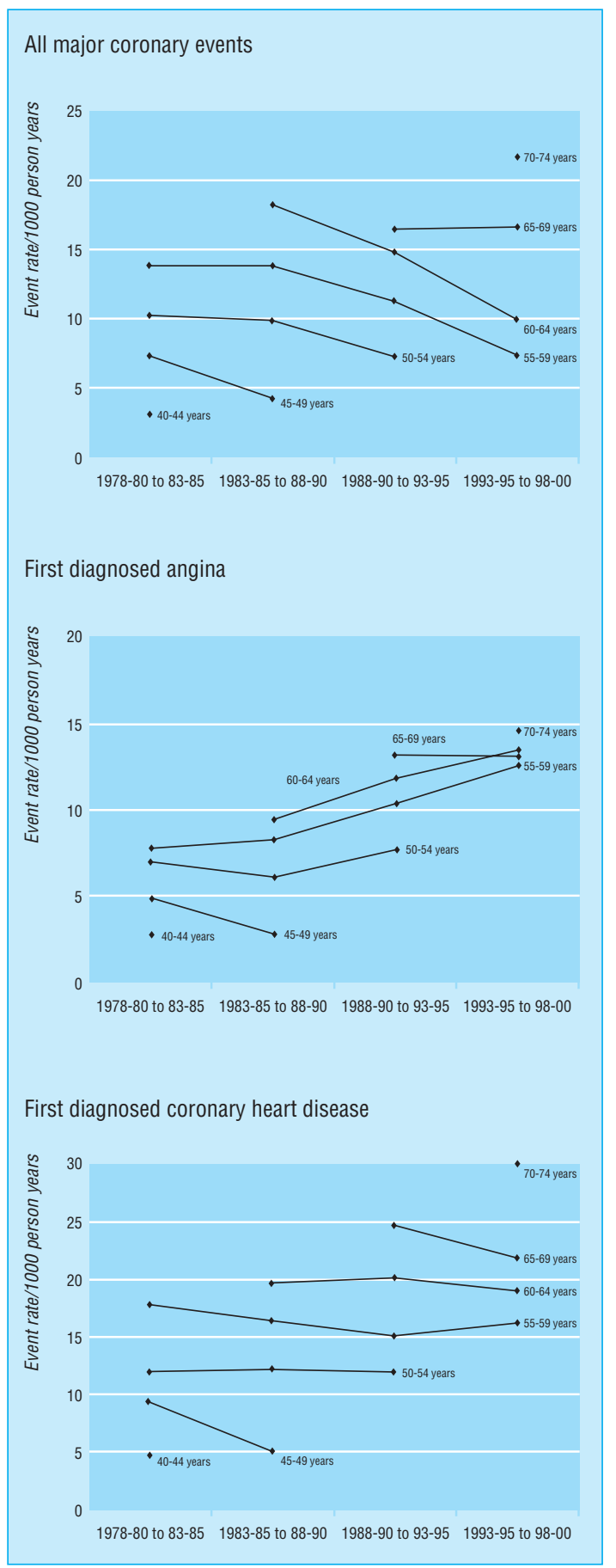

Fig 2 Rates of coronary events (per 1000 person years) by calendar period and age group at start of period

\section{What is already known on this subject}

Death rates due to coronary heart disease have been falling steadily in Britain since the late 1970s

Previous studies have shown that the incidence of major coronary heart disease has also fallen over this period

Much less is known about changes in the incidence of angina; previous studies have only included cases in patients who had been admitted to hospital

\section{What this study adds}

Although rates of major coronary events fell among British men from 1978 to 2000, the incidence of diagnosed angina (ascertained from general practice record reviews) seems to have increased over this period

The opposing trends in major coronary events and angina resulted in no apparent change in the overall incidence of diagnosed coronary heart disease

The increase in incidence of diagnosed angina may be a feature of changes in diagnostic practice rather than a real increase in disease incidence

These results have implications for resources and services for coronary heart disease, especially those for angina

restricted to cases in patients admitted to hospital, the impact of improvements in acute care is limited..$^{21}$

\section{Opposing trends in angina and major coronary heart disease}

Although rates of all categories of major coronary events are continuing to fall among British men, a completely different trend is apparent for diagnosed angina. The rising incidence of diagnosed angina was apparent for uncomplicated angina as well as diagnoses occurring post myocardial infarction, implying that the trend was not solely due to increased survival from previous acute coronary disease. We know of no previous reports of angina incidence trends in Britain based on reviews of medical records from general practices. However, data from the England and Wales general practice morbidity surveys also indicated that secular trends differed for angina compared with myocardial infarction: the rate of consultation for angina increased among men and women in the 1990s compared with the 1980s, while the same statistic for myocardial infarction fell during this time..$^{22}$ In addition, a study based on emergency admissions to hospital in Scotland found that discharge rates for myocardial infarction fell during the 1990s, while those for acute (unstable) angina and other chest pain increased. ${ }^{23}$ These results raise the possibility that the pattern of coronary heart disease is shifting from major events to less severe manifestations of disease.

\section{Is angina increasing in Britain?}

Does the increase in the rate of diagnosed angina seen in our study represent a genuine increase in the incidence of angina in Britain, or is it a feature of changes in diagnostic practice? Evidence from the British Regional Heart Study implies the latter explanation: the prevalence of angina symptoms (assessed by chest pain questionnaire on four occasions and irrespective of diagnosis) fell from 1978-1996, among men with and without a diagnosis of coronary heart disease. ${ }^{3}$ This seems to imply a fall in 
incidence, for angina defined in a standardised way according to symptoms. It is therefore possible that the incidence of angina in the population has genuinely fallen, but that a greater proportion of all angina cases are now formally diagnosed. Such an increase in ascertainment and diagnosis of angina is entirely plausible and may result from general practitioners prioritising the early identification and treatment of coronary heart disease, as well as from an increase in availability of diagnostic investigations for angina-like chest pain. ${ }^{24}$

\section{Conclusions}

The continued decline in the rate of major coronary events among British men is encouraging, and shows that favourable changes in both risk factors and treatment have affected the incidence and prognosis of myocardial infarction. Surprisingly, these changes do not seem to have resulted in a fall in the overall incidence of diagnosed coronary heart disease, because of the increase in the rate of new angina diagnoses. The trend in angina may well be due to diagnostic factors; possibly it will stabilise as diagnosis and investigation of coronary heart disease in Britain reaches a more "optimal" level and the burden of undiagnosed disease falls. Nevertheless, the trend raises concerns from a health service perspective, suggesting that even among middle aged men, resource requirements for angina are not falling. These results emphasise the ongoing need for treatments and services for coronary heart disease, particularly for new angina or suspected angina. They also highlight the need for continued emphasis on the primary prevention of coronary heart disease.

Contributors: FCL, PHW, and RWM developed the original idea for the analysis. FCL performed the analysis and drafted the paper. MW, AGS, and PHW contributed to the design and execution of the British Regional Heart Study. All authors contributed to interpretation of data and the final version of the manuscript. FCL is guarantor.

Funding: The British Regional Heart Study is funded by the British Heart Foundation and the Department of Health (England).

Competing interests: None declared.

Ethical approval: The study was approved at its inception by the Ethics Committee of the Medical Research Council and subsequently by the relevant local and multicentre research ethics committees.

1 Peterson S, Peto V, Rayner M. Coronary heart disease statistics 2004. British Hear Foundation, London, 2004.

2 Tunstall-Pedoe H, Kuulasmaa K, Mahonen M, Tolonen H, Ruokokoski E, Amouyel P, for the WHO MONICA (monitoring trends and determinants in cardiovascular disease) project. Contribution of trends in survival and coronary-event rates to changes in coronary heart disease mortality: 10-year results from 37 WHO MONICA Project in coronary heart disease mortality: 10-yc

3 populations. Lancet 1999;,353:1547-57. Walker M, Ebrahim S, Shaper AG. Is the prevaLampe FC, Morris RW, Whincup PH, Walker M, Ebrahim S, Shaper AG. Is the
lence of coronary heart disease falling in British men? Heart 2001;86:499-505.

4 Murabito JM, Evans JC, Larson MG, Levy D. Prognosis after the onset of coronary heart disease. An investigation of differences in outcome between the sexes according to initial coronary disease presentation. Circulation 1993;88:2548-55.
5 Clarke KW, Gray D, Hampton JR. Implication of prescriptions for nitrates: 7 year follow-up of patients treated for angina in general practice. Br Heart J 1994;71:38-40. 6 Gandhi MM, Lampe FC, Wood DA. Management of angina pectoris in general practice: a questionnaire survey of general practitioners. BrJ Gen Pract 1995;45:11-3.

7 Shaper AG, Pocock SJ, Walker M, Cohen NM, Wale CJ, Thomson AG. British Regional Heart Study: cardiovascular risk factors in middle-aged men in 24 towns. $B M$ J 1981;283:179-86.

8 Shaper AG, Cook DG, Walker M, Macfarlane PW. Recall of diagnosis by men with ischaemic heart disease. Br Heart J 1984;51:606-11.

9 Walker M, Shaper AG, Lennon L, Whincup PH. Twenty year follow-up of a cohort based in general practice in 24 British towns. J Public Health Med 2000;22:479-85.

10 Zou G. A modified Poisson regression approach to prospective studies with binary data. Am J Epidemiol 2004;159:702-6.

11 Walker M, Whincup PH, Shaper AG, Lennon LT, Thomson AG. Validation of patient recall of doctor-diagnosed heart attack and stroke: a postal questionnaire and record review comparison. Am J Epidemiol 1998;148:355-61.

12 Lampe FC, Walker M, Lennon LT, Whincup PH, Ebrahim S. Validity of a self-reported history of doctor-diagnosed angina. J Clin Epidemiol 1999;52:73-81.

13 Gill D, Mayou R, Dawes M, Mant D. Presentation, management and course of angina and suspected angina in primary care. J Psychosomat Res 1999;46:349-58.

14 Salomaa V, Rosamond W, Mahonen M. Decreasing mortality from acute myocardial infarction: effect of incidence and prognosis.J Cardiovascular Risk 1999;6:69-75.

15 Kuulasmaa K, Tunstall-Pedoe H, Dobson A, Fortmann S, Sans S, Tolonen H, et al, for the WHO MONICA Project. Estimation of contribution of changes in classic risk factors to trends in coronary-event rates across the WHO MONICA Project populations. Lancet 2000;355:675-87.

16 Tunstall-Pedoe H, Vanuzzo D, Hobbs M, Mahonen M, Cepaitis Z, Kuulasmaa K, et al, for the WHO MONICA Project. Estimation of contribution of changes in coronary care to improving survival, event rats, and coronary heart disease mortality across the WHO improving survival, event rats, and coronary heart disease

17 Critchley JA, Capewell S, Unal B. Life-years gained from coronary heart disease mortality reduction in Scotland. Prevention or treatment? J Clin Epidemiol 2003;56:583-90. 18 Unal B, Critchley JA, Capewell S. Explaining the decline in coronary heart disease mortality in England and Wales between 1981 and 2000. Circulation 2004;109:1101-7.

19 Salomaa V, Ketonen M, Koukkunen H, Immonen-Raiha P, Jerkkola T, KarjaKoskenkari P, et al. Trends in coronary events in Finland during 1983-1997; the FINAMI study. Eur Heart J 2003;24:311-9.

20 Chambless L, Keil U, Dobson A, Mahonen M, Kuulasmaa K, Rajakangas A, et al, for the WHO MONICA Project. Population versus clinical view of case fatality from acute coronary heart disease. Results from the WHO MONICA Project 1985-1990. Circulacoronary heart disease.
tion 1997;96:3849-59.

21 Capewell S, MacIntyre K, Stewart S, Chalmers JWT, Boyd J, Finlayson A, et al. Age, sex, and social trends in out-of-hospital cardiac deaths in Scotland 1986-95: a retrospective cohort study. Lancet 2001;358:1213-7.

22 Office for National Statistics. Morbidity statistics from general practice, fourth national study, 1991-1992. London: HMSO, 1995.

23 Murphy NF, MacIntyre K, Capewell S, Stewart S, Pell J, Chalmers J, et al. Hospital discharge rates for suspected acute coronary syndromes between 1990 and 2000: population based analysis. BMJ 2004:328:1413-4

24 Wood D, Timmis A, Halinen M. Rapid assessment of chest pain. BMJ 2001;323:586-7.

$$
\text { (Accepted } 3 \text { March 2005) }
$$

bmj.com 2005;330:1046

Department of Primary Care and Population Sciences, Royal Free and University College Medical School, London NW3 2PF

Fiona C Lampe lecturer

Richard W Morris reader

Mary Walker senior lecturer

A Gerald Shaper emeritus professor

Department of Community Health Sciences, St George's Hospital Medical School,

London SW17 ORE

Peter H Whincup professor

Correspondence to: F Lampe f.lampe@pcps.ucl.ac.uk 